\title{
Adult-perpetrated Animal Abuse: Development of a Proclivity Scale
}

\author{
Emma Alleyne, Laura Tilston, Charlotte Parfitt, \& Roxanne Butcher
}

CORE-FP, University of Kent

Please cite as:

Alleyne, E., Tilston, L., Parfitt, C., \& Butcher, R. (2015). Adult-perpetrated animal abuse:

Development of a proclivity scale. Psychology, Crime, \& Law. DOI:

10.1080/1068316X.2014.999064

Correspondence concerning this article should be addressed to Emma Alleyne, Centre of Research and Education in Forensic Psychology, School of Psychology, Keynes College, University of Kent, Canterbury, Kent, CT2 7NP, England. E-mail:

E.K.A.Alleyne@kent.ac.uk 


\begin{abstract}
There is a clear discrepancy in the reporting of animal cruelty complaints, prosecutions and convictions suggesting that any prevalence figures of abuse are significant underrepresentations. Therefore, it can be inferred that there is a large number of animal abusers who are unapprehended. Currently there is no validated tool that assesses the proclivity or propensity to engage in animal abuse amongst members of the general public. Such a tool would enable researchers to study individuals who may think like animal abusers or may be unapprehended offenders themselves. This paper presents the newly developed Animal Abuse Proclivity Scale (AAPS) and some preliminary findings. The results from our two studies show that: (1) the psychometric properties of the AAPS indicate that the scale is a highly reliable measure; (2) the AAPS relates to measures assessing offence-supportive attitudes and reflects the gender differences seen in the literature; and (3) the AAPS demonstrates cross-national validity. These findings support that the AAPS, similar to other offending proclivity measures, is a tool that can be used to examine the factors most related to animal abuse propensity. We discuss how the AAPS can contribute to future developments in theory and practice in the field.
\end{abstract}

Keywords: Animal cruelty, animal abuse proclivity, adult offenders, offence-supportive cognition 
Running head: ANIMAL ABUSE PROCLIVITY

\section{Adult-perpetrated Animal Abuse: Development of a Proclivity Scale}

In England and Wales, over 150,000 animal cruelty complaints were investigated by the Royal Society for the Prevention of Cruelty to Animals (RSPCA; RSPCA, 2013a). These investigations resulted in 3,870 animal cruelty convictions under the Animal Welfare Act 2006. This amounts to less than a 3\% conviction rate. Similar rates are found in Australia (RSPCA, 2013b) and the United States (Humane Society International, 2012). These reports indicate that a very limited number of animal abuse cases result in convictions. These reports also suggest that there are many animal abusers in the community who have not been apprehended. Therefore, measures that can assess a person's proclivity to offend in a particular way enables the development of a research agenda and empirically-led practice to access the most at-risk perpetrators in a meaningful way. Here, we present a vignette-based proclivity measure, the Animal Abuse Proclivity Scale (AAPS), and the first ever reported prevalence of interest in animal abuse and animal abuse behavioral propensity within two samples from two different countries.

The terms animal abuse and animal cruelty have been used inter-changeably in the literature (Gullone, 2012; Tiplady, 2013). Like any other phenomenon studied in the literature, it is vital to be clear on the terminology and definitions used. The debate and discussion of the appropriateness of terminology and definitions are outside the scope of this paper. However, for the sake of clarity, animal abuse will be defined as "all socially unacceptable behavior that intentionally causes unnecessary pain, suffering or distress and/or death to an animal" (Ascione, 1993, p. 83). Furthermore, we focus on animal abuse of companion animals because of their accessibility to the broader public in light of the existing literature (e.g., Arluke \& Luke, 1997) and the current study's research design.

\section{What Do We Know About Adult Perpetrators of Animal Abuse}


Some of the literature has shown an age-related trend when examining the characteristics of animal abuse offenders. That is, some of the findings suggest that animal abuse is more commonly perpetrated by children and adolescents, and this behavior typically declines with age (Gullone, 2012). Other findings suggest a link between age and recurrent animal abuse behavior. Tallichet and Hensley (2005) found that the younger a person first engages in animal abuse, the more likely they will continue abusing animals. As a result, there is a growing literature predominantly focussing on childhood and adolescent perpetration of animal abuse and the progression towards adult interpersonal aggression and violence (e.g., Flynn, 1999, 2011; Kellert \& Felthous, 1985; Tallichet \& Hensley, 2004; Wright \& Hensley, 2003); in spite of this research perspective's critics (e.g., Beirne, 2004). For example, several studies have found that aggressive and violent offenders were more likely than non-violent offenders to have committed acts of animal cruelty during their childhood (e.g., Kellert \& Felthous, 1985; Merz-Perez, Heide, \& Silverman, 2001). However, the literature is inconsistent on whether animal cruelty has sufficient power in predicting specific types of criminal behavior (Walters, 2013).

What we do know from the literature is there appears to be quantitative and qualitative differences in the perpetration of animal abuse. Men are typically more likely than women to engage in animal abuse (e.g., Flynn, 1999), whereas women are typically more concerned about animal welfare (Kendall, Lobao, \& Sharp, 2006). There also appears to be a stronger link between animal cruelty and violent offending amongst women when compared to men. This suggests that gender may act as a moderator in the animal cruelty-offending relationship (Walters, 2013).

Looking beyond demographic characteristics, the literature also tells us that empathy deficits and cognitive biases correlate with animal abuse behavior especially in children (for a review of the literature see Gullone, 2012, 2014). But Tallichet and Hensley (2009) found 
conflicting evidence. That is, empathetic concern (or rather, lack thereof) for the animals abused during childhood was not an important predictor for human-directed aggression in adulthood amongst a sample of inmates. This suggests a much more complex set of distal and proximal risk factors at play and given what the literature tells us about empathy in child perpetrators, it would be equally crucial to evaluate the role of empathy in adult-perpetrated animal abuse.

More importantly, the literature has not been consistent in the proportions of child and adult perpetrators reported. For example, $73 \%$ of perpetrators were found to be older than 18 in Arluke and Luke's (1997) archival study. But it still remains that the research on adultperpetrated animal abuse is disproportionately limited despite some research findings indicating larger proportions of abusers were adults. What we do know is that a significant proportion of the literature has focused on animal abuse in the context of intimate partner violence (IPV) (Allen, Gallagher, \& Jones, 2006; Flynn, 2000; Loring \& Bolden-Hines, 2004). IPV perpetrators engage in this type of behavior in order to: (1) demonstrate power; (2) teach submission; (3) isolate the victim from a support network; (4) express rage at something the victim has done; (5) perpetuate the context of terror; (6) prevent the victim from leaving; (7) punish and terrorize; (8) force or coerce the victim to also engage in the animal abuse; and (9) confirm/reaffirm their power over the victim (Adams, 1995). This abuse is quite prevalent in the context of IPV given that $75 \%$ of women who were victims of IPV and owned pets reported that their intimate partners had threatened or harmed their pets (Flynn, 2011). Moreover, victims of IPV were 11 times more likely than non-victims to report that their pets had been physically hurt or killed (Ascione et al., 2007).

In addition to examining animal abuse within the context of interpersonal violence, there is some literature that has extended the field by investigating which psychological and personality characteristics are distinct to animal abusers. For example, Vaughn et al. (2009) 
found that cruelty towards animals was associated with personality disorders (i.e., obsessivecompulsive disorder, antisocial disorder, and histrionic disorder), substance-related (i.e., alcohol use disorder) and addictive disorders (i.e., pathological gambling). However, it is worthy to note that they did not distinguish between childhood and adult perpetrated animal abuse. Schwartz and colleagues (2012) did not find significant differences between animal abusers and non-abusers on empathy and personality traits. But they did find behavioral and contextual factors to be related. That is, animal abuse was significantly related to bullying behavior whereby animal abusers were more likely to have bullied others in the past or been a victim of bullying themselves (Schwartz, Fremouw, Schenk, \& Ragatz, 2012). These findings highlight the importance of examining the social and psychological factors, and their interdependence, in context.

\section{Measures of attitudes and beliefs supportive of animal abuse}

The literature supports that cognition and cognitive processes facilitate offending behavior by initiating, supporting, and maintaining behavioral choices (Palmer \& Hollin, 2004). So offence-supportive attitudes represent an appropriate indicator of whether a person is likely to engage in the offending behavior. Therefore, measures of offence-supportive attitudes and beliefs are considered to be predictive of antisocial behavior (Gullone, 2012), because "actions are often performed in service of beliefs and values" (Ward, Keown, \& Gannon, 2007, p. 56). The use of self-report methodology has been seen as an effective way of tapping into respondents' perceptual and experiential constructs, whilst minimizing personal distress if presented items of a sensitive or personal nature (Chan, 2009). In line with the context of the current study, the limitations in reporting prevalence of adultperpetrated animal abuse suggests that many perpetrators are unapprehended. Assessing offence-supportive attitudes within the community enables us to potentially better understand the characteristics of the ones that got away. 
One of the first attitudinal scales developed to measure attitudes toward the treatment of animals was the Animal Attitudes Scale (AAS; Herzog, Betchart, \& Pittman, 1991). The scale consisted of 29 items (rated on a five-point Likert-type scale; i.e., strongly agree to strongly disagree) assessing respondents' individual differences in their attitudes. Findings from studies using the AAS include women scoring higher than men participants (Mathews \& Herzog, 1997). That is, women generally endorsed more pro-animal attitudes when compared to their male counterparts. Also, participants who endorsed attitudes in support of the mistreatment of animals were more likely to endorse personality traits indicating a lack of sensitivity. However, personality was also found not to be a major factor in distinguishing respondents' attitudes towards animal abuse (Mathews \& Herzog, 1997).

Henry (2004) followed on from this and developed the Attitudes Towards the Treatment of Animals Scale (ATTAS). This scale consisted of 26 items assessing whether respondents were bothered or not bothered (rated on a five-point Likert-type scale) by different types of animal maltreatment. In line with past aggression research, attitudinal scores diverged by gender when taking into account previous experiences with animals. More specifically, men who had previously witnessed animal cruelty were less bothered by acts of animal abuse than men who had not witnessed animal cruelty before. In contrast, women who had observed animal cruelty previously were more bothered than women with no prior experience of witnessing animal cruelty.

In a follow-up study, Henry (2006) factor-analyzed the ATTAS which resulted in a three factor solution: cruelty, utilitarian, and caregiving. The cruelty subscale assessed respondents' attitudes towards intentionally harming animals without any given reason. The utilitarian subscale assessed respondents' beliefs about using animals as commodities (e.g., research subjects or sources of food). Finally, the caregiving subscale assessed attitudes 
Running head: ANIMAL ABUSE PROCLIVITY

towards animal welfare and well-being responsibilities. Women scored significantly higher than men across all three of these subscales (Henry, 2006).

Whilst these scales are useful in highlighting individual differences in the attitudes towards the treatment of animals, it is difficult to assess whether these attitudes map on to animal abuse behavior. Proclivity measures comprise a growing literature in forensic psychology (most prominently in the sexual offending literature). They have since adopted the design of motor imagery (Jeannerod \& Frak, 1999), which activates the connection between attitudes/beliefs and behavioral intention. This process is achieved by instructing participants to imagine themselves engaging in the offending behavior. This methodology has been used to assess proclivity to engage in sexual harassment (Pryor, 1987; Pryor \& Stoller, 1994), rape (Bohner, Reinhard, Sturm, Kerschbaum, \& Effler, 1998), multiple perpetrator rape (Alleyne, Gannon, Ó Ciardha, \& Wood, 2014), child molestation (Gannon \& O’Connor, 2011), and firesetting behavior (Gannon \& Barrowcliffe, 2012). Of course, not all respondents who endorse an interest in engaging in these behaviors are unapprehended offenders. The added strength of proclivity scales is the opportunity to assess a sample of people who endorse the attitudes and beliefs of actual offenders but successfully employ inhibitory mechanisms (Hall \& Hirschman, 1992) which stops them acting on these interests.

\section{Our Studies}

There is a lack of a systematic method of measuring the prevalence of adultperpetrated animal abuse. As a result, we do not have a clear picture of how many adults engage in this behavior and how many adults are not caught for this behavior. From what we do know, a significant proportion of animal abuse cases are perpetrated by adults and a method of learning more about this group (e.g., the social, psychological, and behavioral factors most related to this behavior) is to use a proclivity measure. Therefore, the current study has five main aims: (1) to develop the Animal Abuse Proclivity Scale (AAPS) that will 
Running head: ANIMAL ABUSE PROCLIVITY

measure the prevalence of interest in animal abuse; (2) to report the proportion of participants that endorse the AAPS scenarios and to see whether the responding differs by gender; (3) to determine whether the AAPS relates to measures that we would expect to be predictors of animal abuse behavior; (4) to examine the psychometric properties of the AAPS; and (5) to further validate the scale by comparing responses from two countries (i.e., the United Kingdom and the USA).

\section{Study 1}

\section{Method}

\section{Participants}

Participants located in the USA were recruited online via Amazon's Mechanical Turk (MTurk). MTurk is an innovative method of recruitment that has three (but not limited to) specific benefits: (1) access to a large participant pool, (2) access to a diverse participant pool, and (3) low cost (Mason \& Suri, 2011). MTurk is also a valid recruitment method. There is evidence demonstrating that MTurk responses are comparable to other forms of online (e.g., Buhrmester, Kwang, \& Gosling, 2011) and offline data collection (e.g., Suri \& Watts, 2011). So from this method, we recruited 213 participants for the current study. The participants were between 18 and 74 years of age $(M=37.10, S D=13.30), 58 \%(n=123)$ were women, and the majority indicated their ethnicity as White $(81 \%)$. The remainder were Black (6\%), Asian (2\%), or Other (11\%). The study consisted of participants completing a series of self-report questionnaires, and in return, they received $\$ 0.70 \mathrm{USD}^{1}$ compensation.

\section{Measures}

The Animal Abuse Proclivity Scale (AAPS). The AAPS was designed based on previous proclivity scales that employ motor imagery in their designs (Jeannerod \& Frak, 1999). We constructed six hypothetical scenarios depicting incidents of animal abuse and

\footnotetext{
${ }^{1}$ This is the standard rate for research participation in studies of similar length.
} 
underlying motivations most commonly found in the literature (see Appendix for full scale). After reviewing the literature, we found that animal abuse can be categorized into two types. Three of the scenarios depicted direct aggression towards animals. For example:

You have just come home from a bad day at work and have a headache. Your pet dog, Rascal, has been left alone all day while you've been at work. You open the door to the living room to find that Rascal, who is normally kept in the kitchen, has managed to open the door into the living room and has chewed a pair of your shoes and urinated on the floor. You pick up one of the chewed shoes and start to hit Rascal on the head in annoyance until the dog is knocked out.

The remaining three scenarios detailed indirect aggression towards animals.

You come home from work to find your partner flirting and touching the estate agent that has come to value your house. You remain calm whilst the estate agent is there, however, when they leave, you confront your partner about the flirting. Your partner insists there was no flirting and that you are being paranoid. This angers you and you start to knock ornaments over and throw things against the wall. To show how annoyed you are, you pick up your partner's pet cat and throw it against the wall in order to scare your partner.

Participants were asked to imagine themselves as the protagonist in each scenario and respond to four questions on a 5-point Likert-type scale. The questions included: (a) "In this situation, how thrilled would you be?"; (b) "In this situation, how powerful would you have felt?"; (c) "In this situation, could you see yourself doing the same?"; and (d) "Imagine that someone had seen you in this situation. How much would you have enjoyed watching their reaction?" These questions assess participants' thrill/excitement towards the scenarios, feelings of power, behavioral propensity to engage in such behaviors, and enjoyment of 
Running head: ANIMAL ABUSE PROCLIVITY

others' reactions. As a result, the AAPS provides the following scores (included are the Cronbach's alphas for the current study):

1. Thrill/excitement towards the direct aggression scenarios (range $=3-15 ; \alpha=.91$ );

2. Thrill/excitement towards the indirect aggression scenarios (range $=3-15 ; \alpha=.90)$;

3. Feelings of power towards the direct aggression scenarios (range $=3-15 ; \alpha=.87$ );

4. Feelings of power towards the indirect aggression scenarios (range $=3-15 ; \alpha=.88$ );

5. Behavioral propensity toward the direct aggression scenarios (range $=3-15 ; \alpha=.85)$;

6. Behavioral propensity toward the indirect aggression scenarios (range $=3-15 ; \alpha=$ $.76)$;

7. Enjoyment of the direct aggression scenarios (range $=3-15 ; \alpha=.92$ );

8. Enjoyment of the indirect aggression scenarios (range $=3-15 ; \alpha=.88$ );

9. A total score for the direct aggression scenarios ( range $=12-60 ; \alpha=.92)$

10. A total score for the indirect aggression scenarios (range $=12-60 ; \alpha=.93)$;

11. An overall interest in animal abuse score (range $=24-120 ; \alpha=.96)$.

Attitudes Towards the Treatment of Animals Scale (ATTAS; Henry, 2004). The ATTAS assesses attitudes towards various types of treatment of animals. Participants respond on a 5-point Likert-type scale indicating how much it would bother them to think about a particular type of animal treatment [e.g., "killing a companion animal (e.g., pet dog, cat, rabbit, etc.) other than to help the animal because it was hurt, old, or sick?; and "failing to provide medical care for a companion animal that is clearly injured or ill?']. Past research has shown that the ATTAS has very good internal consistency $(\alpha=.93)$ and our study further substantiated this $(\alpha=.91)$.

Empathy Quotient Short Version (EQ-SV; Wakabayashi et al., 2006). The EQ-SV is a shortened 22-item version of the original Empathy Quotient (EQ; Baron-Cohen \& Wheelwright, 2004) designed to measure empathy. The original scale has been validated with 
a 'healthy' population and autistic populations and also been found to reliably distinguish between them (Baron-Cohen \& Wheelwright, 2004). The EQ-SV has been found to highly correlate with the original scale $(r=.93)$ suggesting that it measures the core components of empathy (Wakabayashi et al., 2006). The items consist of statements (e.g., "It is hard for me to see why some things upset people so much") and are measured using a 4-point Likert-type scale ranging from strongly agree to strongly disagree with the most empathetic responses scoring 2 points and the least empathetic scoring 0 points. The EQ-SV has shown very good internal consistency in previous research $(\alpha=.90)$ and we had a similar result $(\alpha=.90)$.

Anthropomorphic Tendencies Scale (ATS; Chin et al., 2005). The ATS is a selfreport measure of anthropomorphism when interacting with non-human living beings and objects. Chin et al. (2005) reported that the ATS has four subscales: extreme anthropomorphism (e.g., "A stuffed toy is intelligent like a human is intelligent"), anthropomorphism of pets (e.g., "I treat a pet like a human"), anthropomorphism towards God (e.g., "A God or higher power has a spirit or life-force like people do") and negative anthropomorphism (e.g., "I would yell at a computer if it did something I did not like"). For this study, the extreme anthropomorphism subscale was not included as it was not assessing a sub-construct of anthropomorphism appropriate to compare to the AAPS. The remaining subscales were used together as one composite measure of anthropomorphism. The ATS has not been appropriately validated as of yet, therefore, we were unable to assess the psychometric properties found in previous studies. However, we found that the ATS had good internal consistency in the current study $(\alpha=.87)$.

\section{Procedure}

This study was first approved by the University's Ethics Committee. The questionnaires were administered online and participants were recruited via MTurk. Participants were asked to read an information sheet explaining that the aim of the study was 
to investigate attitudes of the general public towards human interactions with animals to avoid response bias. After indicating their consent on the online form they were asked basic demographic questions and were also requested to state whether they considered themselves as a 'dog person' or a 'cat person' to control for any effects this preference may have. They then proceeded to complete the EQ-SV, ATS, ATTAS, and AAPS in random order to control for order effects. Once they completed the questionnaires, participants were debriefed and informed that the questionnaires had measured their empathy, anthropomorphist attitudes and attitudes toward human interactions with animals. MTurk has a built in functionality for participant payment so participants were provided with a unique code that they used to receive payment $(\$ 0.70 \mathrm{USD})$.

\section{Results}

\section{Self-reported Endorsement of Animal Abuse Scenarios}

The distribution of participant responses on the AAPS and each subscale can be seen in Table 1. Given the literature on gender differences discussed previously we examined whether responding varied as a function of gender. After conducting ANOVAs on the subscales we found that males scored significantly higher than females on the direct aggression subscales behavioral propensity, the enjoyment of watching others react, and the total direct aggression subscale. We also found that males scored significantly higher than females on the indirect aggression subscales thrill, behavioral propensity, the enjoyment of watching others react, and the total indirect aggression subscale. Finally, males scored significantly higher than females on the overall AAPS (see Table 2 for $F$ statistics, $p$ values, and $\omega$ values, and Table 3 for means and standard deviations).

Participants' responses on the AAPS were examined as to whether or not they emphatically rejected an interest in animal abuse. This is consistent with previous proclivity scales in the literature (e.g., Alleyne et al., 2014; Briere \& Runtz, 1989; Gannon \& O’Connor, 
2011). Separated by gender, we found that $62 \%(n=73)$ of female participants and $67 \%(n=$ 59) of male participants showed some level of endorsement of the scenarios (i.e., scored >24). Thus, more than $60 \%$ of male and female participants reported feelings of thrill/excitement, power, behavioral propensity, and/or enjoyment of others' reactions (see Table 3 for all means, standard deviations, and proportions of endorsements).

When we examined the proportion of endorsements broken down by the different types of scenarios, we found that $51 \%(n=63)$ of female participants and $59 \%(n=53)$ of male participants reported some endorsement of the scenarios (i.e., did not emphatically reject an interest in the scenarios) which featured direct aggression towards animals (scored $>12$ on the direct aggression scenarios overall). We also found that $46 \%(n=56)$ of female participants and 50\% $(n=45)$ of male participants reported some endorsement of the scenarios featuring indirect aggression towards animals (scored $>12$ on the indirect aggression scenarios overall). The proportions of endorsements are further broken down by each subscale in Table 3.

\section{The AAPS and Related Measures}

We conducted a linear regression to see which measures related to animal abuse cognition were the strongest predictors of the overall AAPS score and given the gender differences presented above, we also included gender into the regression model. The IVs were gender, ATTAS, EQ-SV, and the ATS, and the sum score on the AAPS was the DV. The regression model was significant, $F(4,20)=5.90, p<.001$, and it explained $8.8 \%$ of the variance. The ATTAS and EQ-SV were both significant predictors of the AAPS overall (see Table 4 for beta coefficients and $p$ values).

\section{Discussion}


In this sample from the USA there are three main findings to report. We found gender differences in most of the subscales of the AAPS whereby male participants scored significantly higher than female participants. We also found large proportions of participants (62\% of females and $67 \%$ of males) had reported some interest in the animal abuse scenarios. When split by scenario type, approximately half of the sample reported some interest in the direct aggression scenarios (51\% of females and 59\% of males) and the indirect scenarios ( $46 \%$ of females and $50 \%$ of males). But a noteworthy finding is that approximately $40 \%$ of male participants reported some endorsement of the behavioral propensity items for both the direct and indirect scenarios; whereas much smaller proportions (20\% for direct scenarios and $24 \%$ for indirect scenarios) of female participants responded in the same way. Finally, we found the AAPS to be significantly related to two out of the four factors expected to be criminogenic - i.e., attitudes that support the mistreatment of animals and low levels of empathy.

\section{Study 2}

\section{Method}

\section{Participants}

To further assess the psychometric properties and also the cross-national validity of the AAPS, we administered the scale at two time points with a sample located in the United Kingdom. Participants were recruited from a University located in South East England. A total of 61 participants took part at Time 1 consisting of $41(67 \%)$ women and a majority indicating their ethnicity to be White $(n=49,80 \%)$. The remaining participants indicated they were Black $(n=3,5 \%)$, Asian $(n=3,5 \%)$, and Other $(n=6,10 \%)$. The mean age of participants was $21.93(S D=4.92$; range $=19-48)$.

Once participants had taken part in Time 1, they were invited to return for a second part of the study. Of those who completed Time 1, 30 returned at least two weeks later to 
Running head: ANIMAL ABUSE PROCLIVITY

complete the AAPS a second time. The participants who took part in both Time 1 and Time 2 of this study received $£ 5$ GBP compensation.

\section{Measures and Procedure}

Participants were provided with an information sheet detailing the study. Similar to Study 1, participants were told that the aim of the study was to investigate attitudes of the general public towards human interactions with animals to avoid response bias. We also explained that this study consisted of two parts and that we would ask them to return for the second part in two weeks.

They were asked basic demographic questions and asked to complete the AAPS. Once they completed the questionnaire, participants were debriefed and asked to return in two weeks for the second part of the study. At Time 2 participants were provided with an information sheet and consent form. They completed the AAPS again in order to be able to assess the test-retest reliability of the scale. Once completed, participants were debriefed once more and given £5GBP for participating in the study.

\section{Results}

\section{Psychometric Properties}

Similar to Study 1, the Cronbach's alphas for the AAPS and its subscales were good. We also conducted test-retest analyses to see if the responses on the AAPS were stable over a two week interval. We found that the overall scale and the subscales had strong correlations between Time 1 and 2 (ranging from $r=.61$ to $r=.98$ ) and all were significant (see Table 5 for the means, standard deviations, Cronbach's alpha coefficients, and test-retest statistics). We also examined whether there was a dropout bias by comparing Time 1 responses of the participants who returned for the second administration with participants who dropped out. We found no significant differences on the AAPS and its subscales (see Table 5 for the means and standard deviations for the dropout and completer groups). 
Running head: ANIMAL ABUSE PROCLIVITY

\section{Cross-national Comparisons}

We conducted ANOVAs to see whether the responses from the USA participants in Study 1 differed from the responses of the current sample from the UK. We found no significant differences for the AAPS and its subscales (see Table 6 for the means, standard deviations, and $F$ statistics).

\section{Discussion}

There are two main findings for this study: (1) test-retest reliabilities of the scales and subscales were all high, along with the $\alpha$ coefficents; and (2) the AAPS has cross-national validity because there were no significant differences in responding from the two countries (i.e., USA and UK). This second study is additional evidence supporting that the AAPS is a valid measure of interest in animal abuse behavior.

\section{Overall Discussion}

The current research consisted of two studies addressing five main aims. Our first aim was to develop a proclivity scale assessing respondents' interest in animal abuse and report the prevalence of such interest. The AAPS was designed as a vignette-based measure consisting of six scenarios. Three scenarios depicted a direct form of animal abuse where the animal was the intended target and three scenarios depicted an indirect form of animal abuse where the animal abuse was meant to elicit an emotional response from another person. The second aim was to report the proportion of participants that did not emphatically reject the scenarios and to see whether the responding differed by gender. In Study 1 we found that $62 \%$ of female participants and $67 \%$ of male participants indicated some endorsement of the animal abuse scenarios. We also found that male participants scored significantly higher on the overall AAPS and many of the subscales (i.e., the behavioral propensity and the enjoyment of others' reactions subscales for the direct aggression scenarios; and the thrill, 
behavioral propensity, and the enjoyment of others' reactions subscales for the indirect aggression scenarios; plus the overall direct and indirect scores).

The third aim was to determine whether constructs expected to be criminogenic factors were related to animal abuse. In Study 1 we found that two factors (i.e., attitudes that support the mistreatment of animals and low levels of empathy) were related to an interest in animal abuse. Our fourth aim was to examine the psychometric properties of the AAPS. In both Studies 1 and 2, the $\alpha$ coefficients were adequate to high (> .76 in Study 1 and $>.62$ in Study 2) indicating the scale's good internal consistency. In Study 2 we also examined the scale's test-retest reliabilities of the scales and subscales and found they were all high (> .61). Finally, we wanted to see if the scale resulted in similar responding cross-nationally (UK vs USA). There were no significant differences in responding from the two samples indicating that the scale has some cross-national (and potentially cultural) validity.

This is the first empirical study assessing interest in animal abuse and behavioral propensity to engage in this behavior in two community-based samples from two different countries. Thus, it is difficult to compare these findings with other studies. Henry (2004) found that approximately $18 \%$ of his sample reported engaging in at least one act of animal abuse. It should be noted, however, Henry (2004) did not distinguish whether the animal abuse was committed during childhood, adolescence or adulthood. This highlights an interesting aspect of our findings. Roughly $20 \%$ of female participants and $40 \%$ of male participants indicated some endorsement of behavioral propensity for the direct and indirect animal abuse scenarios across both studies. This suggests that we have captured a sample of people who indicate a behavioral intention to engage in animal abuse and that this group could be split into those who would actually engage in the behavior and those who want to but inhibitory mechanisms stop them from engaging in animal abuse. Although our data can not speak to whether respondents in our studies will in fact engage in animal abuse. However, 
there are two points to be made in light of these figures. Despite not knowing whether our respondents who indicate some level of behavioral propensity will actually engage in the offending behavior, we know, from other offending literature, that people who self-report offending proclivity also share the same cognitions as found in apprehended offenders (Bohner et al., 1998; Malamuth \& Check, 1980). Therefore, the findings from proclivity research have implications for researching and treating apprehended offenders. The second point to be drawn from these findings is the relevance and importance for future research to examine why some people in the community may think like offenders but do not offend. This subgroup, in theory, is likely to have many of the same risk factors that feed into their selfreported proclivity. But with a scale like the AAPS, researchers can parse out the protective factors and inhibitory mechanisms that distinguish this subgroup from people who do engage in animal abuse.

The scenarios depicting direct and indirect forms of animal abuse were meant to encompass, more broadly and in the simplest terms, the various motivations found in adults who engage in animal abuse. The literature, to date, has predominantly examined animal abuse within the interpersonal aggression contexts (i.e., intimate partner violence; e.g., Allen et al., 2006; Flynn, 2011; McPhedran, 2009). Therefore, the indirect aggression scenarios were designed to be endorsed by respondents who were most likely to displace their interpersonal aggression onto the animal in order to induce an emotional response from the human target (e.g., a partner). In contrast, we wanted to also capture the respondents who were likely to engage in animal abuse directly via the direct scenarios. Although there is little empirical evidence to support this type of abuse, the individual differences and psychopathological literature does suggest that some adults would abuse animals directly as a result of distorted thinking due to, for example, substance abuse and/or personality disorders (Vaughn et al., 2009) and/or endorse attitudes in support of mistreating animals (Henry, 
2004, 2006). Our findings further add support. The AAPS was related to low levels of empathy and attitudes supportive of animal abuse. In conjunction with the similar rates of responding for both scenarios (overall and for each subscale), these findings suggest that direct forms of animal abuse are just as likely to occur as indirect forms. Perhaps, indirect forms are more likely to be reported due to the human target of the displaced aggression being able to report the abuse. Whereas, direct forms would be more likely to occur in private settings and only the perpetrator would be aware of the abuse. These findings speak to why the reporting of animal abuse is extremely low and how difficult it is to assess the reliability of prevalence rates of abuse.

This study is the first to compare responding from two countries, the UK and USA. Research from both countries has suggested similar contexts of abuse and prevalence rates (or lack thereof). The findings of this study confirm that the likelihood of adults to engage in animal abuse is similar in both countries and for the same reasons. However, much more work is needed to examine if cultural differences impact on whether the adults will carry out their indicated behavioral intentions and whether there are local attributes that deter them from engaging in the abuse.

The outcome of this study is a scale that can enable researchers to expand on what we know about adult perpetrators of animal abuse. However, some limitations must be noted. There is a long-standing debate regarding the use of self-report methodology. Self-report data are potentially at the mercy of common method variance (i.e., variance as a result of consistent responding from participants due to the methodology). There is a cost-benefit analysis carried out when developing measures that assess criminal attitudes and antisocial cognition. The design of the AAPS has two strengths that outweigh other designs: (1) the length of time to administer is short and the method is non-invasive when compared to implicit measures; and (2) the literature does support the use of self-report designs when 
assessing perceptual and experiential constructs (see Chan, 2009). Also, the AAPS enables researchers to conduct studies using student samples (an accessible population) and the literature supports inferences made from student data to the wider public (Wiecko, 2010).

We assessed animal preference to see if this had an effect that we can control for (preference had no effect), but there are other factors that were not examined. For example, variables such as previous animal abuse or pet ownership could potentially have a significant effect on animal abuse proclivity. Other variables that were not in the scope of this study but are recognized in the literature are domestic abuse and antisocial behavior. The final limitation was that we did not control for socially desirable responding despite the self-report methodology. This is a factor that we encourage future research to take into account.

Despite the above limitations, the findings of these studies show good promise for future animal abuse research. The AAPS was found to have good internal consistency and test-retest reliability and could be used to assess participants' interest in animal abuse and their behavioral propensity. But most importantly, the AAPS is a tool that could be used to study members of the general public who may think similarly to those who engage in animal abuse. We would like to see future research to include using the scale with apprehended animal abusers so comparisons can be made. There is also a paucity of literature examining the protective factors that inhibit adults from engaging in animal abuse. Future research could examine the similarities and differences between people who indicate a proclivity to engage in animal abuse and carry out that behavioral intention with people who have a propensity but do not engage in the behavior. Finally, the AAPS also has potential practical utility in assessing abuse in the household given the domestic and child abuse literature (DeGue \& DeLillo, 2009). With further validation, the scale could be used to identify adults in the community who are likely perpetrators. This would enable practitioners to target the most atrisk people and implement the appropriate prevention and intervention programs. 


\section{References}

Adams, C.J. (1995). Woman-battering and harm to animals. In C.J. Adams, \& J. Donovan (Eds.), Animals and women: Feminist theoretical explorations (pp. 55-84). Durham, North Carolina: Duke University Press.

Allen, M., Gallagher, B., \& Jones, B. (2006). Domestic violence and the abuse of pets: Researching the link and its implications in Ireland. Practice: Social Work in Action, 18, 167-181. DOI: 10.1080/09503150600904060

Alleyne, E., Gannon, T.A., Ó Ciardha, C., \& Wood, J.L. (2014). Community males show multiple-perpetrator rape proclivity: Development and preliminary validation of an interest scale. Sexual Abuse: A Journal of Research and Treatment, 26, 82-104. DOI: $10.1177 / 1079063213480819$

Arluke, A., \& Luke, C. (1997). Physical cruelty toward animals in Massachusetts, 1975-1996. Society and Animals, 5, 195-204. DOI: 10.1163/156853097X00123

Ascione, F.R. (1993). Children who are cruel to animals: A review of research and implications for developmental psychopathology. Anthrozoos, 6, 226-247. DOI:10.2752/089279393787002105

Ascione, F.R., Weber, C.V., Thompson, T.M., Heath, J., Maruyama, M., \& Hayashi, K. (2007). Battered pets and domestic violence: Animal abuse reported by women experiencing intimate violence and by nonabused women. Violence Against Women, 13, 354-373. DOI: 10.1177/1077801207299201

Baron-Cohen, S., \& Wheelwright, S. (2004). The Empathy Quotient (EQ): An investigation of adults with Asperger Syndrome and high-functioning autism, and normal sex differences. Journal of Autism and Developmental Disorders, 34, 163-175. DOI: 10.1023/B:JADD.0000022607 
Running head: ANIMAL ABUSE PROCLIVITY

Beirne, P. (2004). From animal abuse to interhuman violence? A critical review of the progression thesis. Society and Animals, 12, 39-65. DOI:

$10.1163 / 156853004323029531$

Bohner, G., Reinhard, M.-A., Rutz, S., Sturm, S., Kerschbaum, B., \& Effler, D. (1998). Rape myths as neutralizing cognitions: Evidence for a causal impact of anti-victim attitudes on men's self-reported likelihood of raping. European Journal of Social Psychology, 28, 257-268. DOI:10.1002/(sici)1099-0992(199803/04)28:2<257::aidejsp871>3.0.co;2-1

Briere, J., \& Runtz, M. (1989). University males' sexual interest in children: Predicting potential indices of "pedophilia" in a non-forensic sample. Child Abuse \& Neglect, 13, 65-75. DOI: 10.1016/0145-2134(89)90030-6

Buhrmester, M., Kwang, T., \& Gosling, S.D. (2011). Amazon's Mechanical Turk: A new source of inexpensive, yet high-quality data? Perspectives on Psychological Science, 6, 3-5. DOI: $10.1177 / 1745691610393980$

Chan, D. (2009). So why ask me?-Are self-report data really that bad? In C. E. Lance \&R. J. Vandenber (Eds.), Statistical and methodological myths and urban legends: Received doctrine, verity, and fable in the organizational and social sciences (pp. 309-336). East Sussex, UK: Taylor \& Francis Group.

Chin, M. G., Yordon, R, E., Clark, B, R., Ballion, T., Dolezal, M. J., Shumaker, R., \& Finkelstein, N. (2005). Developing and Anthropomorphic Tendencies Scale. Proceedings of the Human Factors and Ergonomics Society Annual Meeting, 49, 1266-1268. DOI:10.1177/154193120504901311

DeGue, S., \& DiLillo, D. (2009). Is animal cruelty a "red flag" for family violence?: Investigating co-occurring violence toward children, partners, and pets. Journal of Interpersonal Violence, 24, 1036-1056. DOI:10.1177/0886260508319362 
Running head: ANIMAL ABUSE PROCLIVITY

Flynn, C.P. (1999). Animal abuse in childhood and later support for interpersonal violence in families. Society and Animals, 14, 55-69. DOI: 10.1163/156853099X00059

Flynn, C.P. (2000). Woman's best friend: Pet abuse and the role of companion animals in the lives of battered women. Violence Against Women, 6, 162-177. DOI: $10.1177 / 10778010022181778$

Flynn, C.P. (2011). Examining the links between animal abuse and human violence. Crime, Law and Social Change, 55, 453-468. DOI: 10.1007/s10611-011-9297-2

Gannon, T.A., \& Barrowcliffe, E. (2012). Firesetting in the general population: The development and validation of the fire setting and fire proclivity scales. Legal and Criminological Psychology, 17, 105-122. DOI: 10.1348/135532510X523203

Gannon, T. A., \& O'Connor, A. (2011). The Development of the Interest in Child Molestation Scale. Sexual Abuse: A Journal of Research and Treatment. Advance online publication. DOI:10.1177/1079063211412390

Gullone, E. (2012). Animal cruelty, antisocial behaviour and aggression. London, UK: Palgrave Macmillan.

Gullone, E. (2014). Risk factors for the development of animal cruelty. Journal of Animal Ethics, 4, 61-79. DOI: 10.5406/janimalethics.4.2.0061

Hall, G. C. N., \& Hirschman, R. (1992). Sexual aggression against children-A conceptual perspective of etiology. Criminal Justice and Behavior, 19, 8-23. DOI: $10.1177 / 0093854892019001003$

Henry, B.C. (2004). The relationship between animal cruelty, delinquency, and attitudes toward the treatment of animals. Society and Animals, 12, 185-207. DOI: $10.1163 / 1568530042880677$

Henry, B.C. (2006). Empathy, home environment, and attitudes toward animals in relation to animal abuse. Anthrozoos, 19, 17-34. DOI: 10.2752/089279306785593847 
Running head: ANIMAL ABUSE PROCLIVITY

Herzog, H.A., Jr., Betchart, N.S., \& Pittman, R. (1991). Gender, sex role orientation and attitudes toward animals. Anthrozoos, 4, 184-192. DOI:

$10.2752 / 089279391787057170$

Humane Society International. (2012). Animal Use Statistics: Humane Society International. Retrieved from:http://www.hsi.org/campaigns/end_animal_testing/facts/statistics.html

Jeannerod, M., \& Frak, V. (1999). Mental imaging of motor activity in humans. Current Opinion in Neurobiology, 9, 735-739. DOI:10.1016/s0959-4388(99)00038-0

Kellert, S.R., \& Felthous, A.R. (1985). Childhood cruelty toward animals among criminals and noncriminals. Human Relations, 38, 1113-1129.

Kendall, H.A., Lobao, L.M., \& Sharp, J.S. (2006). Public concern with animal well-being: Place, social structural location, and individual experience. Rural Sociology, 71, 399-428. DOI: 10.1526/003601106778070617

Loring, M.T., \& Bolden-Hines, T.A. (2004). Pet abuse by batterers as a means of coercing battered women into committing illegal behavior. Journal of Emotional Abuse, 4, 27-37. DOI: 10.1300/J135v4n01_02

Malamuth, N. M., \& Check, J. V. P. (1980). Penile tumescence and perceptual responses to rape as a function of victim's perceived reactions. Journal of Applied Social Psychology, 10, 528-547. DOI:10.1111/j.1559-1816.1980.tb00730.x

Mathews, S., \& Herzog, H.A., Jr. (1997). Personality and attitudes toward the treatment of animals. Society and Animals, 5, 169-175. DOI: 10.1163/156853097X00060

McPhedran, S. (2009). A review of the evidence for associations between empathy, violence, and animal cruelty. Aggression and Violent Behavior, 14, 1-4. DOI: 10.1016/j.avb.2008.07.005 
Running head: ANIMAL ABUSE PROCLIVITY

Merz-Perez, L., Heide, K.M., \& Silverman, I.J. (2001). Childhood cruelty to animals and subsequent violence against humans. International Journal of Offender Therapy and Comparative Criminology, 45, 556-573. DOI: 10.1177/0306624X01455003

Mera-Perez, L., \& Heide, K.M. (2004). Animal cruelty: Pathway to violence against people. Walnut Creek, CA: AltaMira Press.

Palmer, E.J., \& Hollin, C.R. (2004). The use of the psychological inventory of criminal thinking styles with English young offenders. Legal and Criminological Psychology, 9, 253-263. DOI: 10.1348/1355325041719374

Pryor, J. B. (1987). Sexual harassment proclivities in men. Sex Roles, 17, 269-290. DOI:10.1007/bf00288453

Pryor, J. B., \& Stoller, L. M. (1994). Sexual cognition processes in men high in the likelihood to sexually harass. Personality and Social Psychology Bulletin, 20, 163-169. DOI: $10.1177 / 0146167294202003$

Royal Society for the Prevention of Cruelty to Animals (2013a). Prosecutions Department Annual Report 2013. Retrieved from:

http://www.rspca.org.uk/ImageLocator/LocateAsset?asset=document\&assetId=1232 $\underline{735296611 \& \text { mode }=\text { prd }}$

Royal Society for the Prevention of Cruelty to Animals (2013b). RSPCA Australia Batuibak Statistics 2012-2013. Retrieved from: http://www.rspca.org.au/sites/default/files/website/Thefacts/Statistics/RSPCA_Australia_National_Statistics-2012-2013.pdf

Schwartz, R.L., Fremouw, W., Schenk, A., \& Ragatz, L.L. (2012). Psychological profile of male and female animal abusers. Journal of Interpersonal Violence, 27, 846-861. DOI: $10.1177 / 0886260511423254$ 
Running head: ANIMAL ABUSE PROCLIVITY

Suri, S., \& Watts, D.J. (2011). Cooperation and contagion in web-based, networked public goods experiments. PLoS One, 6, e16836. DOI: 10.1371/journal.pone.0016836

Tallichet, S.E., \& Hensley, C. (2004). Exploring the link between recurrent acts of childhood and adolescent animal cruelty and subsequent violent crime. Criminal Justice Review, 29, 304-316. DOI: 10.1177/073401680402900203

Tallichet, S.E., \& Hensley, C. (2005). Rural and urban differences in the commission of animal cruelty. International Journal of Offender Therapy and Comparative Criminology, 49, 711-726. DOI: 10.1177/0306624X04274186

Tallichet, S.E., \& Hensley, C. (2009). The social and emotional context of childhood and adolescent animal cruelty: Is there a link to adult interpersonal crimes? International Journal of Offender Therapy and Comparative Criminology, 53, 596-606. DOI: 10.1177/0306624X098319417

Tiplady, C. (2013). Animal abuse: Helping animals and people. Oxfordshire, UK: CAB International.

Vaughn, M.G., Fu, Q., DeLisi, M., Beaver, K.M., Perron, B.E., Terrell, K., \& Howard, M.O. (2009). Correlates of cruelty to animals in the United States: Results from the National Epidemiologic Survey on Alcohol and Related Conditions. Journal of Psychiatric Research, 43, 1213-1218. DOI: 10.1016/j.jpsychires.2009.04.011

Wakabayashi, A., Baron-Cohen, S., Wheelwright, S., Goldenfeld, N., Delaney, J., Fine, D., Smith, R., \& Weil, L. (2006). Development of short forms of the Empathy Quotient (EQ-Short) and the Systemizing Quotient (SQ-Short). Personality and Individual Differences, 41(5), 929-940. DOI:10.1016/j.paid.2006.03.017

Walters, G.D. (2013). Testing the specificity postulate of the Violence Graduation Hypothesis: Meta-analyses of the animal cruelty-offending relationship. Aggression and Violent Behavior, 18, 797-802. DOI: 10.1016/j.avb.2013.10.002 
Ward, T., Keown, K., \& Gannon, T.A. (2007). Cognitive distortions as belief, value and action judgments. In T.A. Gannon, T. Ward, A.R. Beech, \& D. Fisher (Eds.), Aggressive offenders' cognition: Theory, research and practice (pp. 53-70). West Sussex, UK: John Wiley \& Sons Ltd.

Wiecko, F.M. (2010). Research note: Assessing the validity of college samples: Are students really that different? Journal of Criminal Justice, 38, 1186-1190. DOI: 10.1016/j.crimjus.2010.09.007

Wright, J., \& Hensley, C. (2003). From animal cruelty to serial murder: Applying the graduation hypothesis. International Journal of Offender Therapy and Comparative Criminology, 47, 71-88. DOI:10.1177/0306624X02239276 
Running head: ANIMAL ABUSE PROCLIVITY

Table 1

Distribution of responses to each scenario of the AAPS

\begin{tabular}{|c|c|c|c|c|c|}
\hline & $\begin{array}{c}\text { Definitely } \\
\text { negative }\end{array}$ & & & & $\begin{array}{c}\text { Definitely } \\
\text { positive }\end{array}$ \\
\hline & 1 & 2 & 3 & 4 & 5 \\
\hline & $\%$ & $\%$ & $\%$ & $\%$ & $\%$ \\
\hline \multicolumn{6}{|l|}{ Scenario 1: Direct } \\
\hline Thrill & 83 & 8 & 4 & 3 & 1 \\
\hline Power & 56 & 14 & 16 & 11 & 2 \\
\hline Behavioral propensity & 84 & 7 & 5 & 4 & 0 \\
\hline Enjoyment & 90 & 2 & 4 & 2 & 1 \\
\hline \multicolumn{6}{|l|}{ Scenario 2: Direct } \\
\hline Thrill & 80 & 13 & 3 & 2 & 1 \\
\hline Power & 59 & 21 & 12 & 8 & 1 \\
\hline Behavioral propensity & 73 & 13 & 7 & 7 & 1 \\
\hline Enjoyment & 87 & 6 & 5 & 2 & 1 \\
\hline \multicolumn{6}{|l|}{ Scenario 3: Direct } \\
\hline Thrill & 88 & 6 & 3 & 2 & 1 \\
\hline Power & 73 & 8 & 10 & 8 & 1 \\
\hline Behavioral propensity & 90 & 3 & 3 & 3 & 1 \\
\hline Enjoyment & 92 & 3 & 3 & 2 & 1 \\
\hline \multicolumn{6}{|l|}{ Scenario 4: Indirect } \\
\hline Thrill & 87 & 6 & 4 & 2 & 1 \\
\hline Power & 72 & 9 & 12 & 5 & 3 \\
\hline Behavioral propensity & 87 & 6 & 3 & 3 & 1 \\
\hline Enjoyment & 89 & 4 & 3 & 3 & 1 \\
\hline \multicolumn{6}{|l|}{ Scenario 5: Indirect } \\
\hline Thrill & 76 & 18 & 3 & 2 & 1 \\
\hline Power & 67 & 17 & 10 & 6 & 1 \\
\hline Behavioral propensity & 72 & 11 & 9 & 7 & 1 \\
\hline Enjoyment & 85 & 8 & 5 & 2 & 1 \\
\hline \multicolumn{6}{|l|}{ Scenario 6: Indirect } \\
\hline Thrill & 90 & 4 & 3 & 2 & 1 \\
\hline Power & 76 & 8 & 8 & 6 & 2 \\
\hline Behavioral propensity & 88 & 5 & 3 & 3 & 0 \\
\hline Enjoyment & 92 & 4 & 3 & 1 & 1 \\
\hline
\end{tabular}


Running head: ANIMAL ABUSE PROCLIVITY

Table 2

ANOVA statistics for gender differences in responses on the AAPS

\begin{tabular}{|c|c|c|c|c|}
\hline & & $F$ & $p$ & $\omega$ \\
\hline \multirow[t]{5}{*}{ Direct } & Thrill & 3.47 & .064 & .11 \\
\hline & Power & 1.01 & .316 & .01 \\
\hline & Behavioral propensity & 5.84 & .017 & .15 \\
\hline & Others' reactions & 4.16 & .043 & .12 \\
\hline & Total & 4.58 & .033 & .13 \\
\hline \multirow[t]{5}{*}{ Indirect } & Thrill & 6.57 & .011 & .16 \\
\hline & Power & .84 & .362 & .03 \\
\hline & Behavioral propensity & 5.87 & .016 & .15 \\
\hline & Others' reactions & 5.26 & .023 & .14 \\
\hline & Total & 5.14 & .024 & .14 \\
\hline Overall & Total & 5.39 & .021 & .15 \\
\hline
\end{tabular}


Running head: ANIMAL ABUSE PROCLIVITY

Table 3

Means, standard deviations, and proportions of endorsements on the AAPS by gender

\begin{tabular}{|c|c|c|c|}
\hline Females & & Overall Mean $(S D)$ & $\begin{array}{l}\% \text { indicating any } \\
\text { endorsement }(n)\end{array}$ \\
\hline \multirow[t]{5}{*}{ Direct } & Thrill & $3.61(1.81)$ & $19(23)$ \\
\hline & Power & $4.99(2.76)$ & $46(57)$ \\
\hline & Behavioral propensity & $3.69(1.88)$ & $20(25)$ \\
\hline & Others' reactions & $3.38(1.52)$ & $9(11)$ \\
\hline & Total & $15.67(6.26)$ & $51(63)$ \\
\hline \multirow[t]{5}{*}{ Indirect } & Thrill & $3.46(1.39)$ & $17(21)$ \\
\hline & Power & $4.50(2.60)$ & $38(47)$ \\
\hline & Behavioral propensity & $3.72(1.71)$ & $24(29)$ \\
\hline & Others' reactions & $3.38(1.47)$ & $12(15)$ \\
\hline & Total & $15.07(5.94)$ & $46(56)$ \\
\hline Overall & Total & $30.74(11.65)$ & $62(73)$ \\
\hline Males & & Overall Mean $(S D)$ & $\begin{array}{l}\% \text { indicating any } \\
\text { endorsement }(n)\end{array}$ \\
\hline \multirow[t]{5}{*}{ Direct } & Thrill & $4.13(2.25)$ & $32(29)$ \\
\hline & Power & $5.39(2.95)$ & $53(48)$ \\
\hline & Behavioral propensity & $4.39(2.28)$ & $41(37)$ \\
\hline & Others' reactions & $3.89(2.07)$ & $20(18)$ \\
\hline & Total & $17.81(8.10)$ & $59(53)$ \\
\hline \multirow[t]{5}{*}{ Indirect } & Thrill & $4.13(2.30)$ & $33(30)$ \\
\hline & Power & $4.85(2.83)$ & $40(36)$ \\
\hline & Behavioral propensity & $4.39(2.25)$ & $40(36)$ \\
\hline & Others' reactions & $3.95(2.08)$ & $26(23)$ \\
\hline & Total & $17.32(8.27)$ & $50(45)$ \\
\hline Overall & Total & $35.19(15.85)$ & $67(59)$ \\
\hline
\end{tabular}


Running head: ANIMAL ABUSE PROCLIVITY

Table 4

Regression statistics for related measures predicting the overall score on the AAPS

\begin{tabular}{lcccc}
\hline & Mean $(S D)$ & $\beta$ & $t$ & $p$ \\
\hline Gender & & -.13 & -1.84 & .068 \\
ATTAS & $23.57(3.96)$ & .19 & 2.67 & .008 \\
EQ-SV & $20.94(8.93)$ & -.21 & -3.01 & .003 \\
ATS & $113.42(17.40)$ & -.10 & -1.40 & .163 \\
\hline
\end{tabular}


Running head: ANIMAL ABUSE PROCLIVITY

Table 5

Psychometric properties, means and standard deviations for the AAPS and its subscales

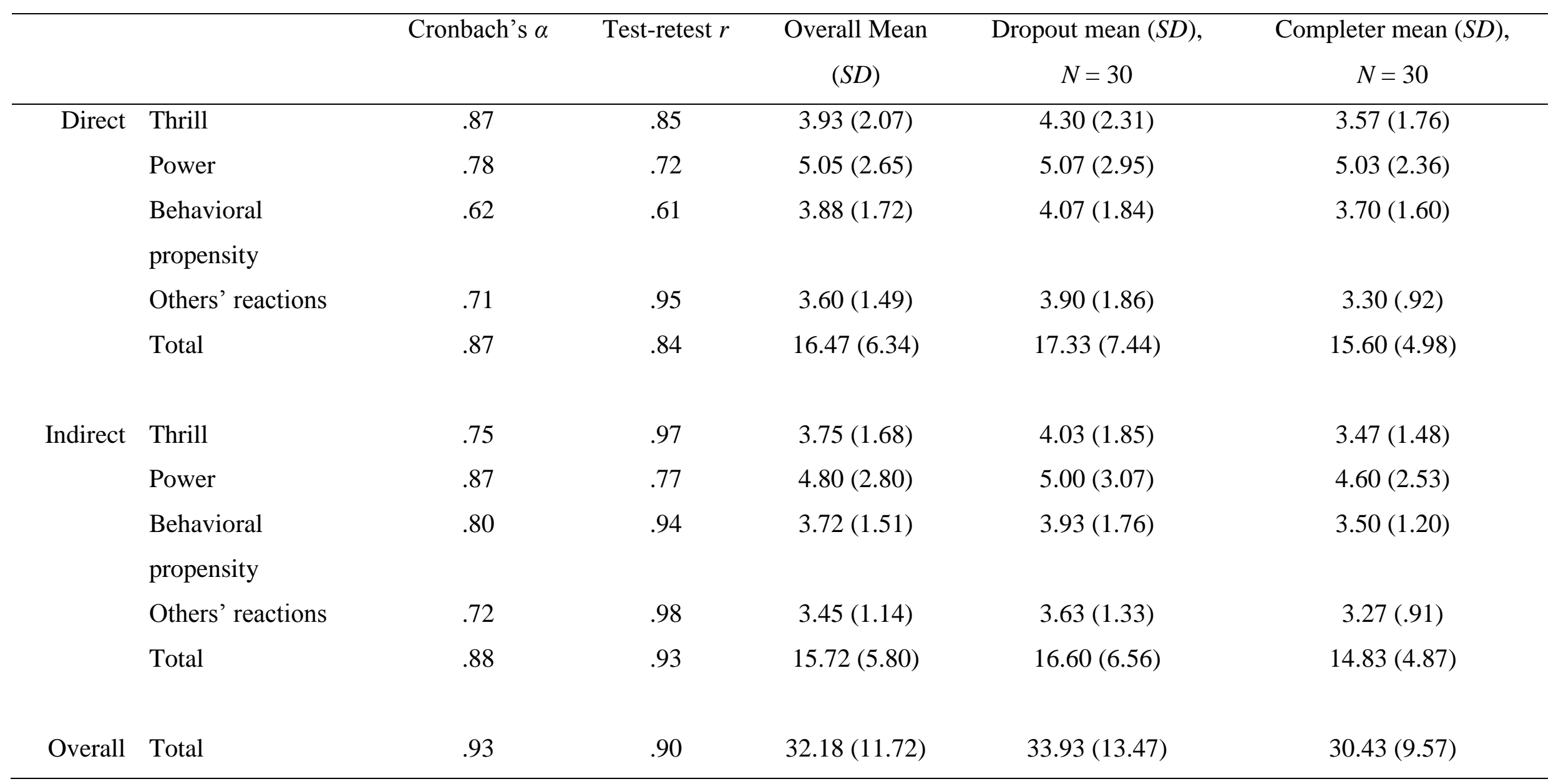


Running head: ANIMAL ABUSE PROCLIVITY

Table 6

Means, standard deviations, and ANOVA statistics for the AAPS and its subscales by country

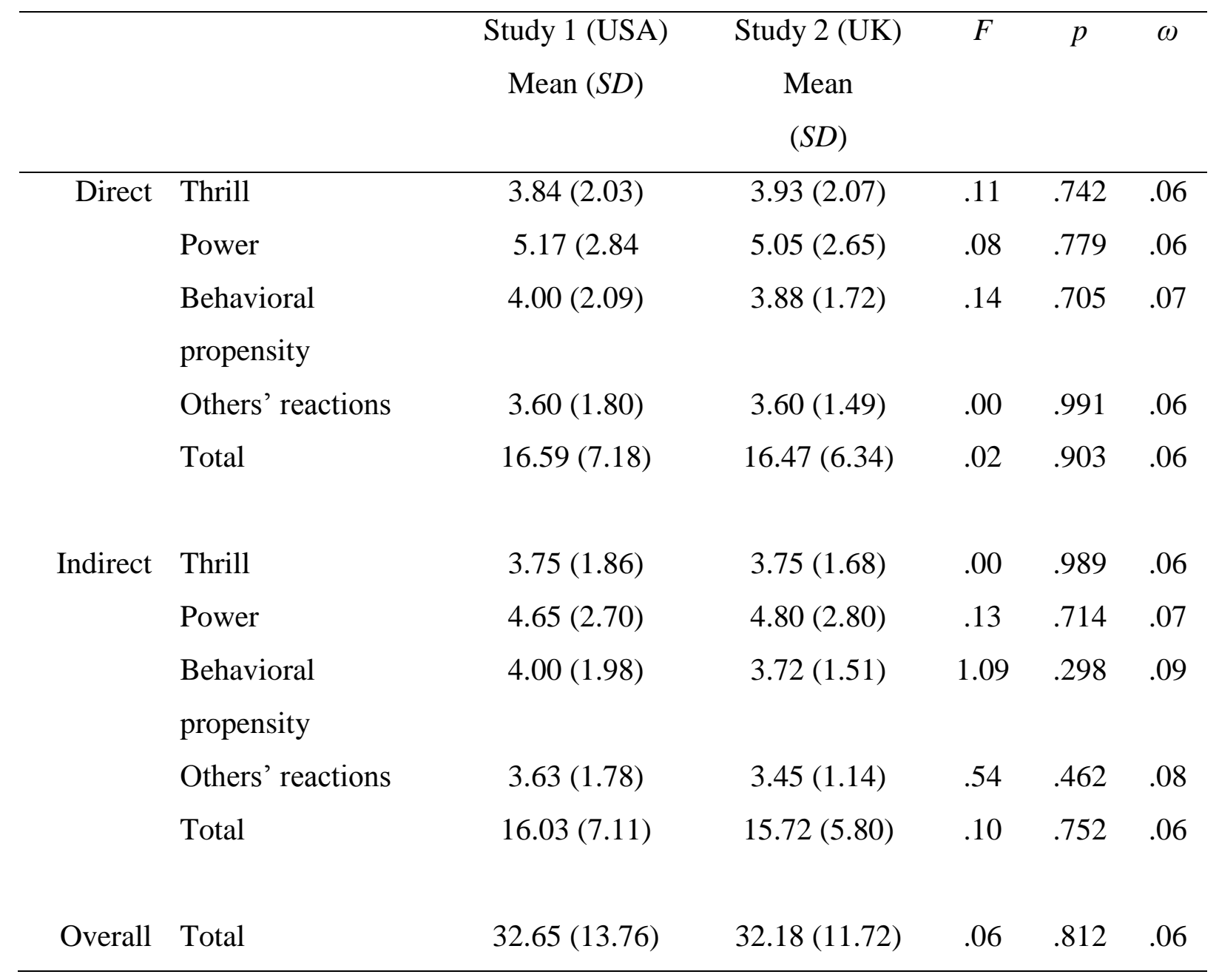




\section{Appendix}

\section{The Animal Abuse Proclivity Scale (AAPS)}

The following scenarios are hypothetical. Please read the text carefully and imagine yourself in the situation presented.

1. You have just come home from a bad day at work and have a headache. Your pet dog, Rascal, has been left alone all day while you've been at work. You open the door to the living room to find that Rascal, who is normally kept in the kitchen, has managed to open the door into the living room and has chewed a pair of your shoes and urinated on the floor. You pick up one of the chewed shoes and start to hit Rascal on the head in annoyance until the dog is knocked out.

2. You are walking through the streets one evening because you are bored and looking for something to do. You spot a dog that had lost its owner wandering around alone. You walk over to the dog however it is cautious of you and begins to bark and snarl at you. You continue to walk up to the dog and you tie it's lead to part of a gate so it can't run away. The dog goes to bite you while you are doing this and so you then kick it away and you continue to kick the dog.

3. You are walking through a park on your way home from a relative's house when you come across a cat that has been injured with no collar. The cat is meowing in distress and is having trouble standing up. You try to assist the cat by making it stand up however the cat hisses in response and won't let you lift it. You find the resistance annoying and instead of leaving the cat there you pick it up by the tail and throw it into a nearby pond.

4. You come home from work to find your partner flirting and touching the estate agent that has come to value your house. You remain calm whilst the estate agent is there however when they leave, you confront your partner about the flirting. Your partner insists there was no flirting and that you are being paranoid. This angers you and you start to knock ornaments over and throw things against the wall in annoyance. To show how annoyed you are, you pick up your partner's pet cat and throw it against the wall in order to scare your partner.

5. You have a test at university tomorrow that is worth a big percentage of your final grade. You are trying your hardest to revise for it, however your next door neighbour is playing music at an unreasonably high volume. You have tried moving to another room in the house but it is still very loud and annoying. You are getting very frustrated and upset with your neighbour because you are unable to revise in peace. Your pet cat comes into the room meowing to try and get your attention but you ignore it as you are trying to concentrate. It then jumps up in front of you and blocks the view of your textbooks. In anger, you pick the cat up and kick it out of the room.

6. You have recently been told by your manager at work that there is a high chance that you might be made redundant as the company is having a lot of financial difficulties. You are having trouble with money yourself and have suggested to your partner numerous times that getting rid of the pet dog would be a good way to save money. This has caused a lot of fighting at home as your partner is being unreasonable by refusing to give up the dog. The stress of this has made you increasingly frustrated 
and angry and so one evening, you decide to take matters into your own hands. You kick the dog so it becomes dazed and then take it to the car and dump it at the side of a road.

Each scenario would be followed by the questions below:

Now please read the following questions, circling the answer most applicable to yourself:

1. In this situation, how thrilled would you be?

\begin{tabular}{ccccc}
\hline 1 & 2 & 3 & 4 & 5 \\
\hline $\begin{array}{c}\text { Not at all } \\
\text { thrilled }\end{array}$ & $\begin{array}{c}\text { Not particularly } \\
\text { thrilled }\end{array}$ & Don't know & Fairly thrilled & $\begin{array}{c}\text { Very strongly } \\
\text { thrilled }\end{array}$
\end{tabular}

2. In this situation, how powerful would you have felt?

\begin{tabular}{ccccc}
\hline 1 & 2 & 3 & 4 & 5 \\
\hline $\begin{array}{l}\text { Not at all } \\
\text { powerful }\end{array}$ & $\begin{array}{c}\text { Not particularly } \\
\text { powerful }\end{array}$ & Don't know & Fairly powerful & Very powerful
\end{tabular}

3. In this situation, could you see yourself doing the same?

\begin{tabular}{ccccc}
\hline 1 & 2 & 3 & 4 & 5 \\
\hline $\begin{array}{c}\text { Would } \\
\text { definitely not } \\
\text { have done the }\end{array}$ & $\begin{array}{c}\text { Would probably } \\
\text { not have done } \\
\text { the same }\end{array}$ & Don't know & $\begin{array}{c}\text { Would probably } \\
\text { have done the } \\
\text { same }\end{array}$ & $\begin{array}{c}\text { Would definitely } \\
\text { have done the } \\
\text { same }\end{array}$
\end{tabular}

same

4. Imagine that someone had seen you in this situation. How much would you have enjoyed watching their reaction?

\begin{tabular}{ccccc}
\hline 1 & 2 & 3 & 4 & 5 \\
\hline $\begin{array}{c}\text { Would not enjoy } \\
\text { at all }\end{array}$ & $\begin{array}{c}\text { Would not } \\
\text { particularly } \\
\text { enjoy it }\end{array}$ & Don't know & $\begin{array}{c}\text { Would rather } \\
\text { enjoy it }\end{array}$ & $\begin{array}{c}\text { Would greatly } \\
\text { enjoy it }\end{array}$ \\
\end{tabular}

